\title{
Le
}

SECCIÓN: Educación y espacio
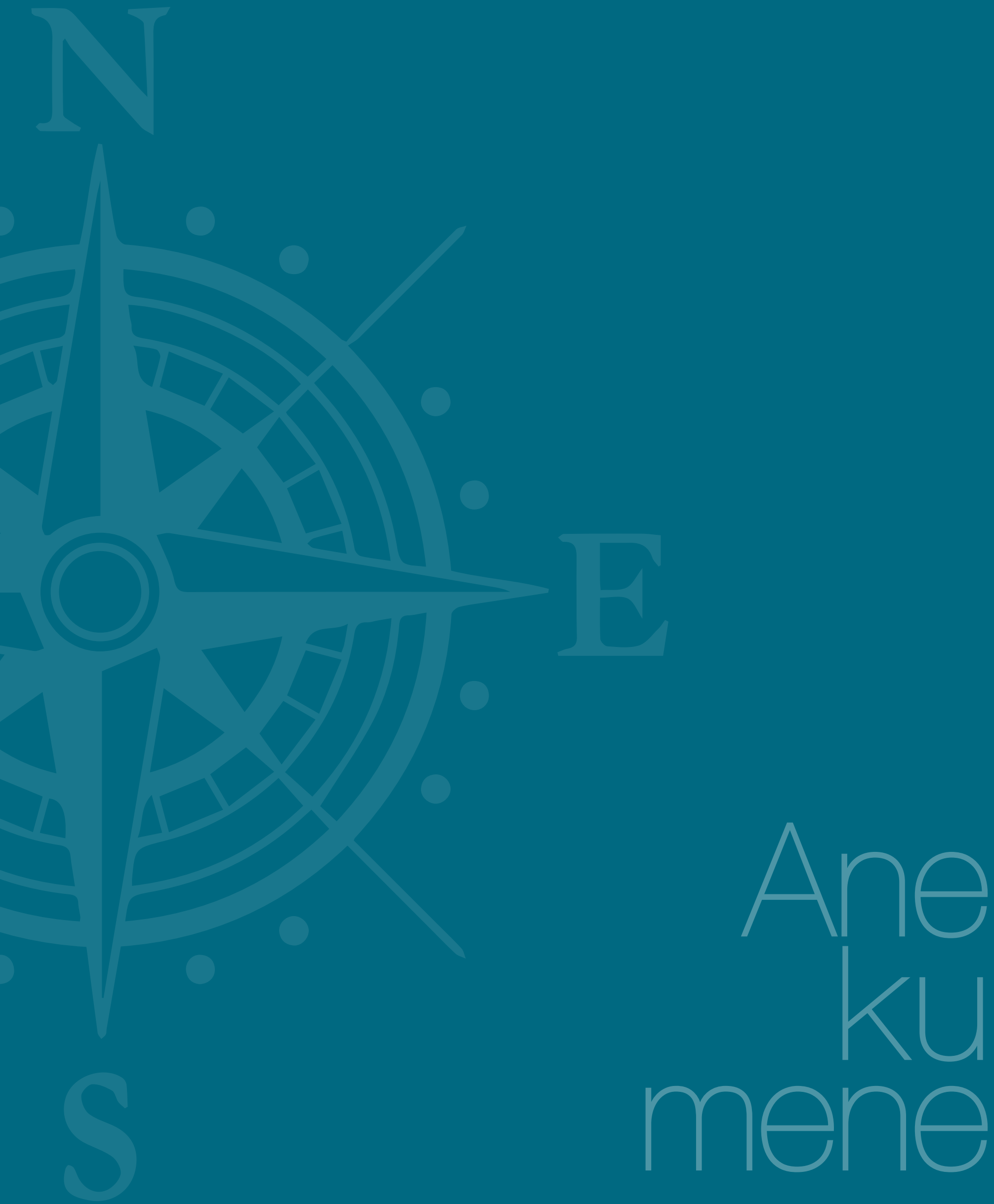


\section{O programa de uma disciplina de teoria e método em geografia ou acerca de um passeio pelos bosques do alheamento}

The Program of a Subject on Theory and Method in Geography or about a Walk through the Woods of Alienation

El programa de una disciplina de teoría y método en geografía o acerca de un paseo por los bosques de la alienación

Manoel Fernandes de Sousa Neto*

\section{Resumo}

O programa de uma disciplina de Teoria e Método em Geografia é apresentado aos/às estudantes como proposta de percurso neste ensaio, que busca refletir os motivos pelos quais fazemos escolhas didáticas e modos de melhor realizar os processos de ensino-aprendizagem.
Palavras-chave

Programa; disciplina; didática 


\section{Abstract}

The program of a subject about Theory \& Method in Geography is presented to students as a proposed course in this essay, which aims to reflect the reasons why we make choices in didactics and the best ways to carry out the teaching-learning processes.

\section{Resumen}

El programa de una disciplina de Teoría y Método en Geografía es presentado a los estudiantes como propuesta de recorrido en este ensayo, que busca reflejar los motivos por los cuales hacemos nuestras elecciones didácticas y de las mejores maneras de llevar a cabo los procesos de enseñanza-aprendizaje.

\section{Keywords}

Program; subject; didactics

\section{Palabras clave}

Programa; disciplina; didáctica 
Ao longo de quatro, quase cinco meses, o professor encontra, pelo menos uma vez por semana, os estudantes com quem partilha seus pontos de vista, suas aprendizagens teóricas, suas vivências na arte de ensinar ou professar algo aos outros. Boa parte do percurso partilhado é, em grande medida, resultado do processo de vir a saber no convívio com outros estudantes, em outros momentos históricos e mediante um sem número de erros, imprecisões, desacordos, distintas interpretações e maturações intelectuais.

O fato é que o professor nunca está pronto e esta falha de fabricação ou pecado original é, em verdade, seu maior aliado. 0 professor, nesse sentido, vai à sala de aula para aprender e para aprender muitas coisas que nunca ouviu ou viveu, bem como para aprender diferente o que tantas vezes repetiu com outras conexões cognitivas e sob o brilho de diferentes olhares. A destessitura permanente desse sujeito é a principal marca de seu constructo, é como se a sala de aula fosse uma espécie de Penélope a espera de Ulisses.

O programa que se apresenta no primeiro encontro é, em função disso, uma mera carta de intenções, uma espécie de convite à sua própria reescrita, um tipo de possibilidade e, consequentemente, tem um estatuto provisório. O programa é apresentado para ir, ao longo das aulas, sendo construído de outro modo, desfeito junto com o docente que o elaborou e isso a partir das relações que se estabelecem nessa arena de debates, nessa ágora das palavras, contendas, novidades, descobertas, desencantamentos em que conflitam visões de mundo diversas e se constroem opiniões, posições, leituras divergentes do mesmo mundo. O programa, aparentemente pronto, está sempre por ser feito.

É comum, por exemplo, que o mesmo programa, apresentado pelo professor de uma disciplina redivivas vezes à diferentes turmas, torne-se distinto como experiência e resulte em vários outros programas. Em sendo assim, ainda que usando os mesmos textos, na mesma sequência, mediante o mesmo conjunto de problemas e objetivos, não se realize o mesmo processo, porque a aprendizagem realiza-se como relação, socialmente e conflituosamente.

Vocês já tornaram, por sua própria condição de existência, este programa que lhes apresento, em outro programa. Em pensando assim, realizamos não um programa em si, mas um movimento programático, uma elaboração que necessita mesmo como princípio e, desde o princípio, negar o que é formalmente proposto.

Lembro-me de uma cena antológica no filme A Sociedade dos Poetas Mortos (1989), na qual o professor pede que os estudantes rasguem seus livros. A metáfora ai é um tanto para dizer: creiam menos naquilo que está pronto, reinventem, reescrevam, sejam sujeitos, não sejam indiferentes, nem aceitem ser homogeneizados. Fique claro, não estou a propor que rasguem nada por enquanto, até por lembrar de um personagem que é descrito no belíssimo À Mesa com o Chapeleiro Maluco: ensaios sobre corvos e escrivaninhas (2009), de Alberto Manguel. O personagem em questão, Joseph Joubert, rasga as páginas que não gosta dos livros que lê, o que o faz ter uma biblioteca com livros menos volumosos, claro, expressão apenas daquilo que achou interessante ao ler e, embora tenham sido impressos centenas, milhares de livros similares aos seus, só os seus tem agora o formato e as páginas que a sua crítica permitiu, permanecessem habitando sua biblioteca particular.

Essa história permite-me dizer-lhes duas coisas: rasguem ou queimem apenas depois de ter lido algo pelo menos uma vez e sejam leitores críticos de todas as páginas, livros, programas, sociedades, mundo que lerem. É quiçá, por esse motivo, que duas recordações mais se assomem a esta digressão que agora faço acerca do programa que lhes ofereço.

A primeira delas diz respeito ao Como se faz uma tese (2014), de Umberto Eco, livro que deliciosamente nos propõe pensar como devemos escolher um tema de pesquisa e enfrentar o problema de realizar uma investigação. Ali, em meio aos conselhos que dá, há um que acho jocoso e maravilhoso: o de que mesmo para realizar plágios é preciso ler, realizar uma criteriosa pesquisa, certificar-se de que o seu leitor não leu antes aquilo que agora você apresenta como seu.

A segunda vem de Gilles Deleuze e Felix Guattarri, ao dizer na Introdução: Rizoma de seu Mil Platôs: capitalismo e esquizofrenia que "um livro existe apenas pelo fora e no fora" (1995, p.94). Um livro só existe, em outras palavras, a partir da leitura que dele os leitores fazem e é por esse motivo que nunca cessam de aparecer leituras críticas novas sobre textos, livros e ideias antigas que se renovam, são reinventados, são reescritos a partir do leitor. Quiçá, por isso, as páginas dos livros de certos leitores sejam outras, repletas das anotações, conexões, desenhos, sublinhamentos, marcas que serpenteiam e os tornam únicos, mais densos, mais completos.

A impropriedade no caso aqui é seguir o curso proposto por um programa como se tudo corresse bem e de maneira ordenada. Como um modelo, uma régua, uma lei. Há, no entanto, que se apresentar um programa, e ele inicia todas estas nossas trajetórias negativas. Um programa se faz a partir de algo que lhe é bem maior e diz respeito a um currículo manifesto, prescrito, que em suas linhas estabelece o tipo de profissional que o diálogo entre os programas das diversas disciplinas propõe, como projeto, formar. Porém, fique claro, o currículo é sempre território de conflitos, projetos em disputa, movimento contraditório.

O programa que lhes apresento, portanto, precisa ser pensado como totalidade e, como totalidade, imerso e mediado, vinculado ao processo de formação que nega em si as formas com as quais nos é apresentado de modo aparente.

A proposta é que pensemos a teoria e o método para Geografia como inseridos em um processo de elaboração intelectual que não se desvin- 
cula da própria materialização da disciplina como práxis que foi e que é parte do mundo, participante do mundo, situada no mundo, situante do mundo. Discurso, disciplina, ciência, profissão, relação, herança, ideologia. A Geografia tem uma história que não pode ser contada fora da história da humanidade, nem entendida como apartada das necessidades sócio-históricas da humanidade, que enquanto saber disciplinar, buscou de alguma maneira explicar ou responder.

Em sendo dessa maneira, resolvemos encetar o programa por entender que a Geografia do mundo tal como nós o concebemos só poderia vir a ser formulada a partir da existência deste mesmo mundo. A própria existência de um conjunto de problemas e respostas para o mundo exigia que ele existisse como totalidade física. 0 que não quer dizer que não houvesse desde a filosofia pré-socrática, dos saberes de diversas outras culturas em distintas latitudes, tentativas de explicar o mundo a partir do mundo que se tinha como coisa concreta e imaginação possível.

A Geografia, a Física, a Filosofia, a Química, a Matemática não estavam separadas como formas estanques de perceber o mundo à época da cultura helênica, por exemplo, e a disciplinarização do pensamento é, pois, em grande dose, resultado da destruição daquele mundo fragmentário pensado como todo e da construção fragmentária desse mundo todo pensado de maneira disciplinarizada. É por esse motivo que um outro elemento do presente programa que lhes apresento é buscar entender que as teorias e os métodos são formulados mediante a moldura de seu tempo, mas ultrapassam seu tempo ao serem necessárias à formulação daquelas teorias e métodos que agora usamos e permanecem como um problema.

Um movimento exemplificador desse processo histórico do pensamento é que a lógica formal permanece e se desenvolveu enormemente, compondo um conjunto de explicações para o mundo que aparece, por exemplo, na econometria que realiza, a partir de certa negação formal da economia política clássica, a leitura de um mundo baseado em números, estatísticas, equações e tendências que se explicam por eles mesmos objetiva e abstratamente. A lógica dialética faz à lógica formal uma crítica violenta, destrutiva, para demonstrar os seus limites explicativos, para explicitar os seus riscos políticos, mas, ao mesmo tempo e em um só movimento, se apoia sobre seus ombros para superá-la. Dizendo de outro modo, a lógica dialética busca afirmar a lógica formal no mesmo movimento em que a nega e sem a qual não se poderia realizar.

Um programa, como nosso ponto de partida, apresenta uma ementa, que é uma espécie de síntese do programa, aquilo que deve ser tratado ao longo dos dias em que nos encontraremos aqui para dialogar. A ementa da disciplina numerada com o código FLG 0132 é intitulada como Teoria e Método da Geografia I (Universidade de São Paulo, 2001), lecionada regularmente no segundo semestre letivo do primeiro ano curricular, com caráter obrigatório e carga horária de sessenta e quatro créditos, com os temários resumidamente manifestos como programa mínimo em sete itens, a saber:

1. Noções de Teoria do Conhecimento. Senso comum e Ciência. $\mathrm{O}$ ato cognitivo. Objeto e método. Conhecimento e ideologia.

2. A Ciência Moderna e seus fundamentos filosóficos.

3. O Positivismo Clássico: fundamentos, propostas e avaliações. O Positivismo Clássico na Geografia.

4. O Neo-kantismo: fundamentos, propostas e avaliações. O Neokantismo na Geografia.

5. O Marxismo: fundamentos, propostas e avaliações. O Marxismo na Geografia.

6. O Positivismo Lógico: fundamentos, propostas e avaliações. O Positivismo Lógico na Geografia.

7. A Fenomenologia: fundamentos, propostas e avaliações. A Fenomenologia na Geografia.

A guisa desse roteiro de viagem pintado em largas tintas, baralhamos, partindo das nossas leituras e apropriações teórico-metodológicas, os temas a partir dos quais desejamos ler este programa mínimo. Assim, as aulas estão propostas em meio a um calendário que é, certo modo, o mapa das nossas travessias de aprendizagens. Um pouco a exemplo daquela ponte de que fala Marco Polo a Kublai Kahn no livro Cidades Invisíveis (1990), de Ítalo Calvino. Quando o grande conquistador mongol, ao ter pedido que o viajante descrevesse cada uma das pedras que compunha a ponte, recebe, como resposta, que pouco interessam as pedras e mais importa o arco que juntas todas elas conformam e que, enfim, sustenta, no seu lugar, cada uma delas.

A relação aqui com esse processo de vir-a-saber busca propor leveza em todo peso que possa haver. Por isso os temas das aulas lembram coisas outras além de si, e são elas: 1) tempo e espaço na economia-mundo; 2) quando surge a quarta parte: às voltas com um mapa mundi do século XVI; 3) O Geógrafo de Johannes Vermeer: arte, corografia e geografia; 4) os projetos de esclarecimento; 5) o par antigo/moderno; 6) o pós-moderno, o pós-colonial e a geografia; 7) lógica formal e lógica dialética: olhar o mundo de diferentes maneiras; 8) teoria e práxis: breve passeio sobre a ideia de totalidade; 9) positivismos e geografia; 10) historicismos e geografia; 11) fenomenologias e geografia; 12) estruturalismo e geografia; 13) ontologias e geografia; 14) marxismo e geografia e 15) geografia contemporânea.

A proposição para seguir um caminho como este é já o de que os geógrafos não podem ser formados apenas pela geografia, nem podem ter como finalidade a geografia que aprendem. Embora dentro de uma 
lógica de disciplinarização do pensamento, precisamos fugir à ditatura da disciplina, à sua ordenação epistemológica herdada, ainda que reconheçamos a sua existência, as suas possibilidades e os limites que possui.

É por motivos como esses que as aulas se dividem em momentos e visam realizar movimentos em que lemos, falamos, discutimos, escrevemos, repensamos, avaliamos nossos processos no interior deles. Esse ato de ler com os outros a partir das leituras que temos, visa a um só tempo recuperar e transgredir estas leituras.

Os momentos que propomos para as aulas visam torná-las poeticamente vinculadas entre si. Por isso vamos valsear entre cinema e literatura, música e poesia, teoria e método, leitura e escrita, crítica e autocrítica.

\begin{abstract}
A forma como isso se apresenta é de termos um momento inicial de exposição, seguido daquilo que gostamos de nomear como uma pausa para prosa em que se levantam as questões acerca dos textos lidos e da reflexão inicial feita sobre eles, em uma espécie de polifonia, cujo fundamento é o exercício da crítica. Depois, mas ainda não por fim, o ato da escrita a cada encontro como possibilidade de enfrentar, como “Mallarmé chamava [a] 'assustadora brancura da página'." (Manguel, 2009, p. 81) e manchar o papel de ideias, proposições, leituras.
\end{abstract}

É isso, que torna possível sugerir, para o entreaulas, uma música dodecafônica, um filme de Bollywood, um mestre da literatura na periferia do capitalismo e estar às voltas com a construção de imagos mundi conceituais muito interessantes e, quem sabe, inaugurais.

\section{Referências}

Calvino, Í., (1990). Cidades invisíveis. Tradução Diogo Mainardi. São Paulo: Companhia das Letras.

Deleuze, G., \& Guatuarri, F., (1995). Mil Platôs: capitalismo e esquizofrenia. Volume 1. (A. Guerra Neto e C. Pinto Costa ,Trad.). Rio de Janeiro: Ed. 34.

Eco, U., (2014) Como se faz uma tese. G. Cardozo de Souza Trad. 25a ed. São Paulo: Perspectiva.

Junger P. \& Thomas T., (produtores). Weir P. (diretor). (1989). Sociedade dos Poetas Mortos. [Filme].Estados Unidos: Disney/Buena Vista.

Manguel, A., (2009) À(2009), Ana Vistaas Mortosusp.br/graduacao/apoio/FLG132.txto/FLG132. (J. V. Baptista, Trad.). São Paulo: Cia. das Letras.

Universidade de São Paulo (2001). Ementa da disciplina Teoria e Método da Geografia I. Disponível em http://www. geografia.fflch.usp.br/graduacao/apoio/FLG132.txt 